\title{
Effects of Thiazolidinedione and New Antidiabetic Agents on Stroke
}

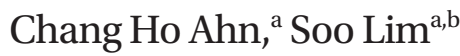

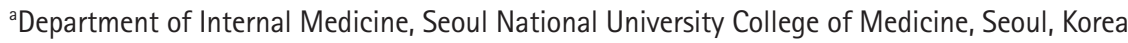 \\ ${ }^{b}$ Department of Internal Medicine, Seoul National University Bundang Hospital, Seoul National University College of Medicine, Seongnam, Korea
}

Patients with hyperglycemia are at a high risk of cardio- and cerebrovascular diseases. Diabetes patients also have poor outcomes after cerebrovascular disease development. Several classes of drugs are used for diabetes management in clinical practice. Thiazolidinedione (TZD) was introduced in the late 1990s, and new antidiabetic agents have been introduced since 2000. After issues with rosiglitazone in 2007, the U.S. Food and Drug Administration strongly recommended that trials investigating cardiovascular risk associated with new antidiabetic medications should be conducted before drug approval in the United States, to prove the safety of these new drugs and to determine their superiority to previous medications. Currently, results are available from two studies with TZD focusing on cardiovascular diseases, including stroke, and from 12 cardiovascular outcome trials focusing on major adverse cardiovascular events associated with new antidiabetic agents (four with dipeptidyl peptidase-4 inhibitors, three with sodium-glucose cotransporter-2 inhibitors, and five with glucagon-like peptide- 1 analogues). These studies showed different results for primary cardiovascular outcomes and stroke prevention. It is important to determine whether prescription of TZD or new antidiabetic medications compared to conventional treatment, such as sulfonylurea or insulin, is better for stroke management. Furthermore, it is unclear whether drugs in the same class show greater safety and efficacy than other drugs for stroke management.

Keywords Stroke; Diabetes mellitus; Thiazolidinediones; Dipeptidyl-peptidase IV inhibitors; Sodiumglucose transporter 2; Glucagon-like peptide 1

\author{
Correspondence: Soo Lim \\ Department of Internal Medicine, Seoul \\ National University Bundang Hospital, \\ Seoul National University College of \\ Medicine, 82 Gumi-ro 173beon-gil, \\ Bundang-gu, Seongnam 13620, Korea \\ Tel: +82-31-787-7035 \\ Fax: +82-31-787-4051 \\ E-mail:limsoo@snu.ac.kr \\ Received: January 3, 2019 \\ Revised: April 1, 2019 \\ Accepted: April 5, 2019
}

\section{Introduction}

Diabetes management requires coordinated efforts to change the patient's lifestyle to include a heathy diet and regular exercise, and to manage multiple risk factors, to prevent or delay complications such as stroke. ${ }^{1-3}$ Patients with hyperglycemia or diabetes mellitus (DM) are at high risk of cerebrovascular ischemic stroke. ${ }^{4,5} \mathrm{DM}$ is also associated with poor outcome in patients with cerebral hemorrhage. ${ }^{6}$ However, it is unclear whether it is better to prescribe intensive glucose-lowering treatment than conventional treatment for stroke manage- ment, and whether specific antidiabetic agents are safer and more efficacious than other drugs for stroke management.

Here, we discuss the mechanisms underlying the relationship between glucose homeostasis and stroke development, and provide an overview of the efficacy of glucose-lowering treatment in stroke management. We also discuss evidence from recent large clinical trials of thiazolidinedione (TZD) and new antidiabetic medications such as dipeptidyl peptidase-4 (DPP4) inhibitors, sodium-glucose cotransporter-2 (SGLT2) inhibitors, and glucagonlike peptide-1 (GLP1) analogues, which suggest the potential of these agents in primary and secondary stroke prevention. 


\section{Glucose metabolism and stroke}

The association between DM and stroke involves the interplay of complex mechanisms, including various hemodynamic and metabolic pathways (Figure 1). DM is characterized by chronic low-grade inflammation, oxidative stress, endothelial dysfunction, hypercoagulability, dyslipidemia, and insulin resistance. These factors contribute individually and collectively to diabetic macrovascular complications. Three distinct pathways are involved in diabetes-associated increased vasculopathy: increased production of advanced glycosylation end products (AGEs), ${ }_{1}^{8}$ increased reactive oxygen species (ROS) production and oxidative damage to vessels, ${ }^{9}$ and activation of the aldose reductase pathway, which is driven by high blood glucose concentration. ${ }^{10}$ Activation of protein kinase C (PKC) isozymes is also involved in diabetes-related vascular complications. ${ }^{10}$

High circulatory glucose concentrations facilitate the nonenzymatic glycosylation of proteins in the blood vessel walls, resulting in AGE formation. Binding of AGE to its receptors aggravates atherogenicity by accelerating oxidation and uptake of low density lipoprotein (LDL). ${ }^{8}$ Hyperglycemia stimulates the upregulation of AGEs. Moreover, nuclear factor KB and activator protein-1 increase proatherogenic gene expression and recruit numerous mediators of atherogenesis, including white blood cells, adhesion molecules, monocyte chemoattractant protein-1, and other inflammatory cytokines."

Hyperglycemia-induced ROS generation and insulin resistance damage vascular smooth muscle and endothelial cells. ${ }^{12}$ Superoxide anions neutralize nitric oxide (NO) by forming peroxynitrite ions, which decrease the bioavailability of endothelium-derived NO. ${ }^{13}$ This inhibits endothelium-mediated vasodilation, stimulates abnormal platelet activation, and increases vascular smooth muscle cell proliferation and migration (Figure 1). ROS also increases LDL oxidation in vessel walls. ${ }^{13}$

Evidence suggests the role of PKC activation in hyperglycemiainduced vascular and endothelial dysfunction. ${ }^{10}$ Glucose transported into vascular cells stimulates de novo synthesis of diacylglycerol and PKC activation. PKC isoforms activation stimulates proatherosclerotic gene expression and vascular cell proliferation and migration, and impairs NO-mediated vasodilation. PKC acti-

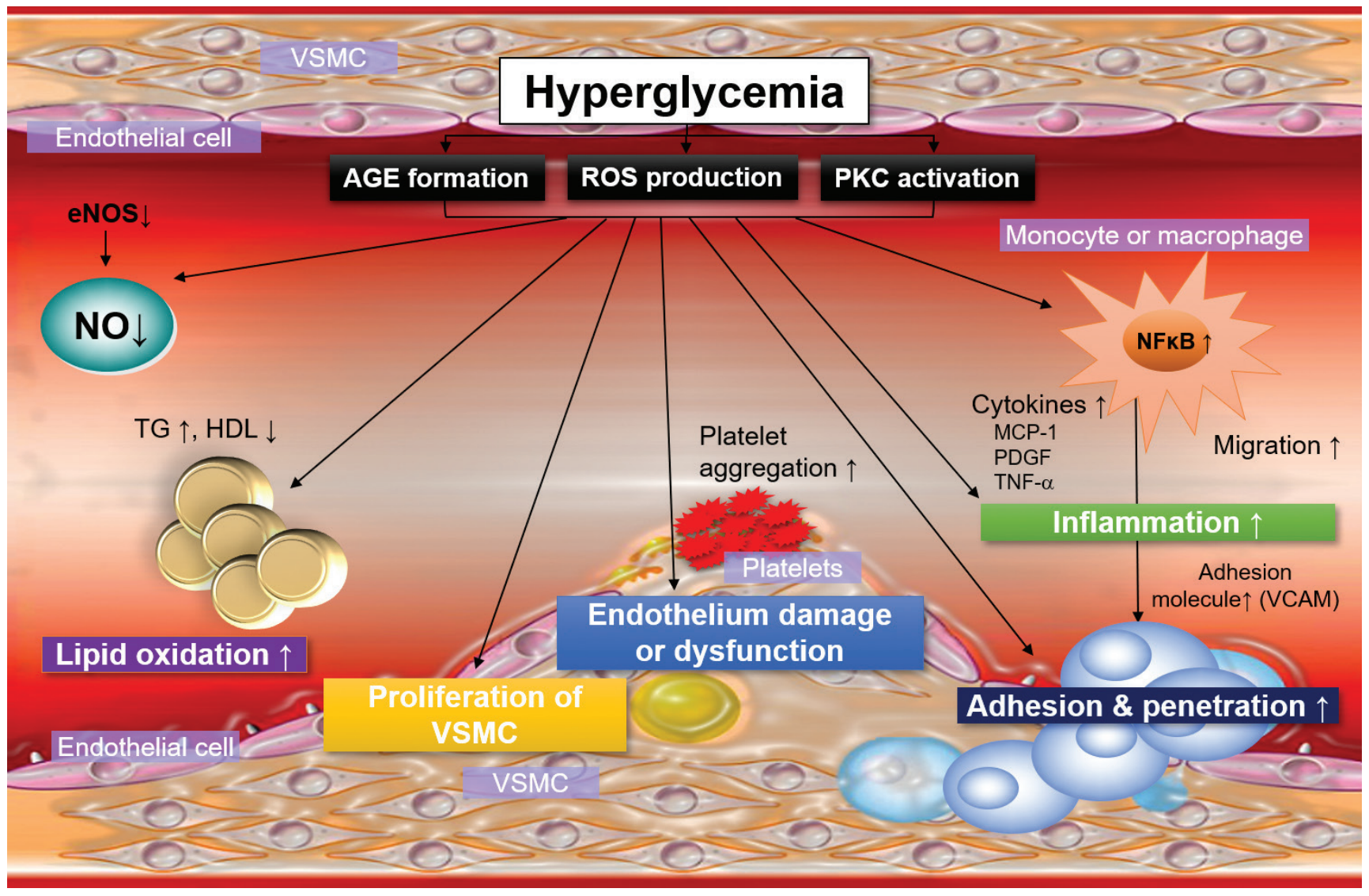

Figure 1. Pathogenic mechanisms for the involvement of hyperglycemia in the development of atherosclerotic cerebrovascular diseases. VSMC, vascular smooth muscle cell; AGE, advanced glycosylation end product; ROS, reactive oxygen species; PKC, protein kinase C; eNOS, endothelial nitric oxide synthase; $\mathrm{NO}$, nitric oxide; TG, triglyceride; $\mathrm{HDL}$, high density lipoprotein; $\mathrm{NFKB}$, nuclear factor $\mathrm{KB}$; $\mathrm{MCP}-1$, monocyte chemoattractant protein-1; PDGF, platelet-derived growth factor; TNF-a, tumor necrosis factor-a; VCAM, vascular cell adhesion molecule. 
vation also increases vascular endothelial cell permeability. ${ }^{14}$

The relationship between direct clinical risk factors and their roles in stroke development is illustrated in Figure 2. In addition to hyperglycemia and insulin resistance, high blood pressure, dyslipidemia, and smoking are implicated in the pathogenesis of stroke by increasing peripheral resistance and accelerating atherosclerosis. High urinary albumin excretion is another independent predictor of stroke in diabetes patients. ${ }^{15}$ These factors aggravate inflammation and increase oxidative stress, leading to endothelial dysfunction, increased thrombotic activity, and accelerated vascular smooth muscle cell proliferation and migration. These processes contribute to thrombus formation and plaque progression, which increase stroke risk.

Diabetic autonomic neuropathy and retinopathy are also risk factors for stroke. ${ }^{16,17}$ Therefore, several clinical factors are involved in increasing stroke risk.

\section{Ideal approach to decreasing the risk of cardiovascular outcomes in diabetes patients}

Evidence for the beneficial effects of intensive glycemic control in preventing cardiovascular diseases is inconclusive. However, intensive glycemic control as a part of a multifactorial intervention for atherosclerotic risk factors was effective in reducing cardiovascular disease risk and overall mortality in the Steno-2 study ${ }^{1,18}$ and cerebrovascular disease risk in the Japan Diabetes Outcome Intervention Trial 3 (J-DOIT3) study. ${ }^{19}$ The Ste-

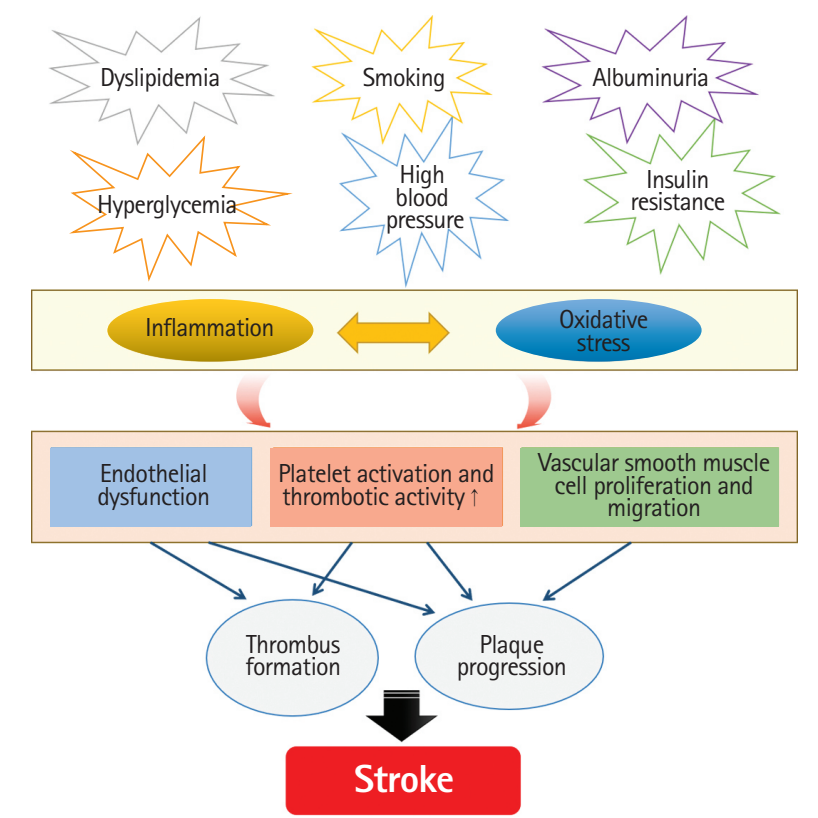

Figure 2. Contributing risk factors and their roles in the development of stroke. no-2 trial was the first to investigate the impact of multifactorial interventions in patients with type 2 diabetes (T2D), even though the sample size was small $(n=160)$. Investigators treated study participants with multiple pharmacological agents and implemented lifestyle modifications that targeted hyperglycemia, hypertension, dyslipidemia, and microalbuminuria. This multifactorial intervention with intensive glycemic control (target glycosylated hemoglobin [HbA1c] level <6.5\%) reduced the incidence of the composite cardiovascular endpoint (hazard ratio [HR], 0.47; 95\% confidence interval [Cl], 0.24 to 0.73 ; $P=0.008)^{18}$ and overall mortality $(\mathrm{HR}, 0.54 ; 95 \% \mathrm{Cl}, 0.32$ to $0.89 ; P=0.02) .{ }^{1}$ Another study involving Japanese patients with diabetes (the J-DOIT3 study) included an intensified intervention with tight glycemic control (target $\mathrm{HbA} 1 \mathrm{c}<6.2 \%$ ). This study observed substantial benefit for cerebrovascular event prevention, including stroke and the need for carotid endarterectomy, percutaneous transluminal cerebral angioplasty, and carotid artery stenting, compared with that associated with conventional therapy (target $\mathrm{HbA} 1 \mathrm{c}<6.9 \%$ ) in patients with T2D ( $\mathrm{HR}, 0.42 ; 95 \% \mathrm{Cl}, 0.24$ to $0.74 ; P=0.002) .{ }^{19}$ The success of multifactorial intervention trials in reducing atherosclerotic vascular disease risk suggests the complex multifactorial nature of atherosclerosis. Therefore, focusing on a single risk factor may not be sufficient to alter its progression.

Mechanistically, severe hypoglycemia may aggravate brain injury ${ }^{20}$ because the brain uses glucose as its primary fuel. Intensive glucose lowering with antidiabetic medications that do not induce hypoglycemia is helpful in stroke prevention. In addition, hyperglycemia increases stroke risk even in prediabetes patients. ${ }^{21}$ Therefore, controlling hyperglycemia to achieve normal glucose levels may be beneficial to prevent cerebrovascular disease.

TZD and new antidiabetic agents such as DPP4 inhibitors, SGLT2 inhibitors, and GLP1 analogues do not induce hypoglycemia. This may be why an active glucose-lowering approach with these agents was shown to be neutral (DPP4 inhibitors) or beneficial (TZD, SGLT2 inhibitors, and several GLP1 analogues) on cardiovascular outcomes compared with the effects of previous agents such as sulfonylurea and insulin. Optimal glucose control that does not induce hypoglycemia may therefore be the ideal approach to achieve better cerebrovascular outcomes.

\section{Randomized controlled trials with TZD and new agents}

The results of stroke in randomized controlled trials (RCTs) with TZD and new antidiabetic agents are summarized in Table 1. 
Table 1. Stroke events in recent cardiovascular outcome studies of antidiabetic medications

\begin{tabular}{|c|c|c|}
\hline Drug (study name) & Stroke events & $\mathrm{HR}(95 \% \mathrm{Cl})$ \\
\hline \multicolumn{3}{|l|}{ TZD } \\
\hline Pioglitazone (PROactive) ${ }^{24}$ & Stroke & $0.81(0.61-1.07)$ \\
\hline Pioglitazone (IRIS) $)^{26 *}$ & Stroke & $0.82(0.61-1.10)$ \\
\hline \multicolumn{3}{|l|}{ DPP4 inhibitors } \\
\hline Saxagliptin (SAVOR-TIMI) ${ }^{30}$ & Ischemic stroke & $1.11(0.88-1.39)$ \\
\hline Alogliptin (EXAMINE) $)^{31}$ & Nonfatal stroke & $0.91(0.55-1.50)$ \\
\hline Sitagliptin (TECOS) $)^{32}$ & Fatal or nonfatal stroke & $0.97(0.79-1.19)$ \\
\hline Linagliptin (CARMELINA) ${ }^{33}$ & Fatal or nonfatal stroke & $0.91(0.67-1.23)$ \\
\hline \multicolumn{3}{|l|}{ SGLT2 inhibitors } \\
\hline Empagliflozin (EMPA-REG OUTCOME) & Fatal or nonfatal stroke & $1.18(0.89-1.56)$ \\
\hline Canagliflozin (CANVAS) ${ }^{36}$ & Fatal or nonfatal stroke & $0.87(0.69-1.09)$ \\
\hline Dapagliflozin (DECLARE-TIMI58) ${ }^{37}$ & Ischemic stroke & $1.01(0.84-1.21)$ \\
\hline \multicolumn{3}{|l|}{ GLP1 analogues } \\
\hline Lixisenatide (ELIXA) ${ }^{43}$ & Stroke & $1.12(0.79-1.58)$ \\
\hline Once weekly exenatide (EXSCEL) ${ }^{44}$ & Fatal or nonfatal stroke & $0.85(0.70-1.03)$ \\
\hline Liraglutide (LEADER) ${ }^{40}$ & Fatal or nonfatal stroke, or TIA & $0.86(0.71-1.06)$ \\
\hline Semaglutide (SUSTAIN-6) $)^{41}$ & Nonfatal stroke & $0.61(0.38-0.99)$ \\
\hline Albiglutide (HARMONY Outcome) ${ }^{42}$ & Nonfatal stroke & $0.86(0.66-1.14)$ \\
\hline
\end{tabular}

$\mathrm{HR}$, hazard ratio; $\mathrm{Cl}$, confidence interval; TZD, thiazolidinedione; PROactive, PROspective pioglitAzone Clinical Trial In macroVascular Events; IRIS, Insulin Resistance Intervention after Stroke; DPP4, dipeptidyl peptidase-4; SAVOR-TIMI, Saxagliptin Assessment of Vascular Outcomes Recorded in Patients with Diabetes Mellitus-Thrombolysis in Myocardial Infarction; EXAMINE, Examination of Cardiovascular Outcomes with Alogliptin versus Standard of Care; TECOS, Trial Evaluating Cardiovascular Outcomes with Sitagliptin; CARMELINA, Cardiovascular and Renal Microvascular Outcome Study With Linagliptin in Patients With Type 2 Diabetes Mellitus; SGLT2, sodium-glucose cotransporter-2; EMPA-REG OUTCOME, Empagliflozin, Cardiovascular Outcomes, and Mortality in Type 2 Diabetes; CANVAS, CANagliflozin CardioVascular Assessment Study; DECLARE-TIMI58, Dapagliflozin Effect on CardiovascuLAR Events-Thrombolysis in Myocardial Infarction 58; GLP1, glucagon-like peptide-1; ELIXA, Evaluation of Lixisenatide in Acute Coronary Syndrome; EXSCEL, Exenatide Study of Cardiovascular Event Lowering; LEADER, Liraglutide Effect and Action in Diabetes: Evaluation of Cardiovascular Outcome Results; TIA, transient ischemic attack; SUSTAIN-6, Trial to Evaluate Cardiovascular and Other Long-term Outcomes with Semaglutide 6; HARMONY, albiglutide and cardiovascular outcomes in patients with type 2 diabetes and cardiovascular disease.

*IRIS study recruited participants with insulin resistance, but without type 2 diabetes mellitus.

\section{TZDs}

The beneficial effects of TZDs have been shown in clinical studies through carotid ultrasonography to measure carotid intimamedia thickness (IMT), a surrogate marker of cerebrovascular diseases. Carotid IMT progression was significantly attenuated after treatment with rosiglitazone, a TZD, for 48 weeks compared with that after placebo treatment $(-0.012 \mathrm{~mm}$ vs. 0.031 $\mathrm{mm}$, respectively; $P=0.03$ ) in non-diabetes patients. ${ }^{22}$ In patients with T2D, carotid IMT decreased significantly more after pioglitazone treatment for 24 weeks $(-0.054 \mathrm{~mm})$ than after glimepiride treatment $(-0.002 \mathrm{~mm}, P<0.005) .{ }^{23}$ These changes were accompanied by insulin resistance attenuation. TZDs may therefore act as insulin sensitizers and play a role in preventing or regressing atherosclerosis, particularly in the carotid artery.

The PROspective pioglitAzone Clinical Trial In macroVascular Events (PROactive) study is a prospective, double-blind study of 5,238 patients with T2D with a history of macrovascular disease. In this study, pioglitazone did not reduce composite car- diovascular outcome risk, including death from any cause, nonfatal myocardial infarction, stroke, acute coronary syndrome, leg amputation, coronary revascularization, or leg revascularization (HR, 0.90; event rate: $19.7 \%$ [514/2,605] for pioglitazone vs. $21.7 \%[572 / 2,633]$ for placebo; $95 \% \mathrm{Cl}, 0.80$ to 1.02$).{ }^{24}$ The rates of stroke did not differ between the two groups ( $H R, 0.81$; event rate: $3.3 \%[86 / 2,605]$ in the pioglitazone group vs. $4.1 \%[107 / 2,633]$ in the placebo group; $95 \%$ $\mathrm{Cl}, 0.61$ to 1.07) (Figure 3). In a later analysis of patients from the PROactive study with previous stroke, the rate of fatal or nonfatal stroke events was significantly lower in the pioglitazone group than that in the placebo group $(H R, 0.53$; event rate: $5.6 \%$ in the pioglitazone group vs. $10.2 \%$ in the placebo group; $95 \% \mathrm{Cl}, 0.34$ to 0.85$).^{25}$

The Insulin Resistance Intervention after Stroke (IRIS) study evaluated the efficacy of pioglitazone in 3,876 non-diabetes patients who previously experienced ischemic stroke or transient ischemic attack (TIA). ${ }^{26}$ Pioglitazone therapy reduced the 


\section{Primary CV outcome}

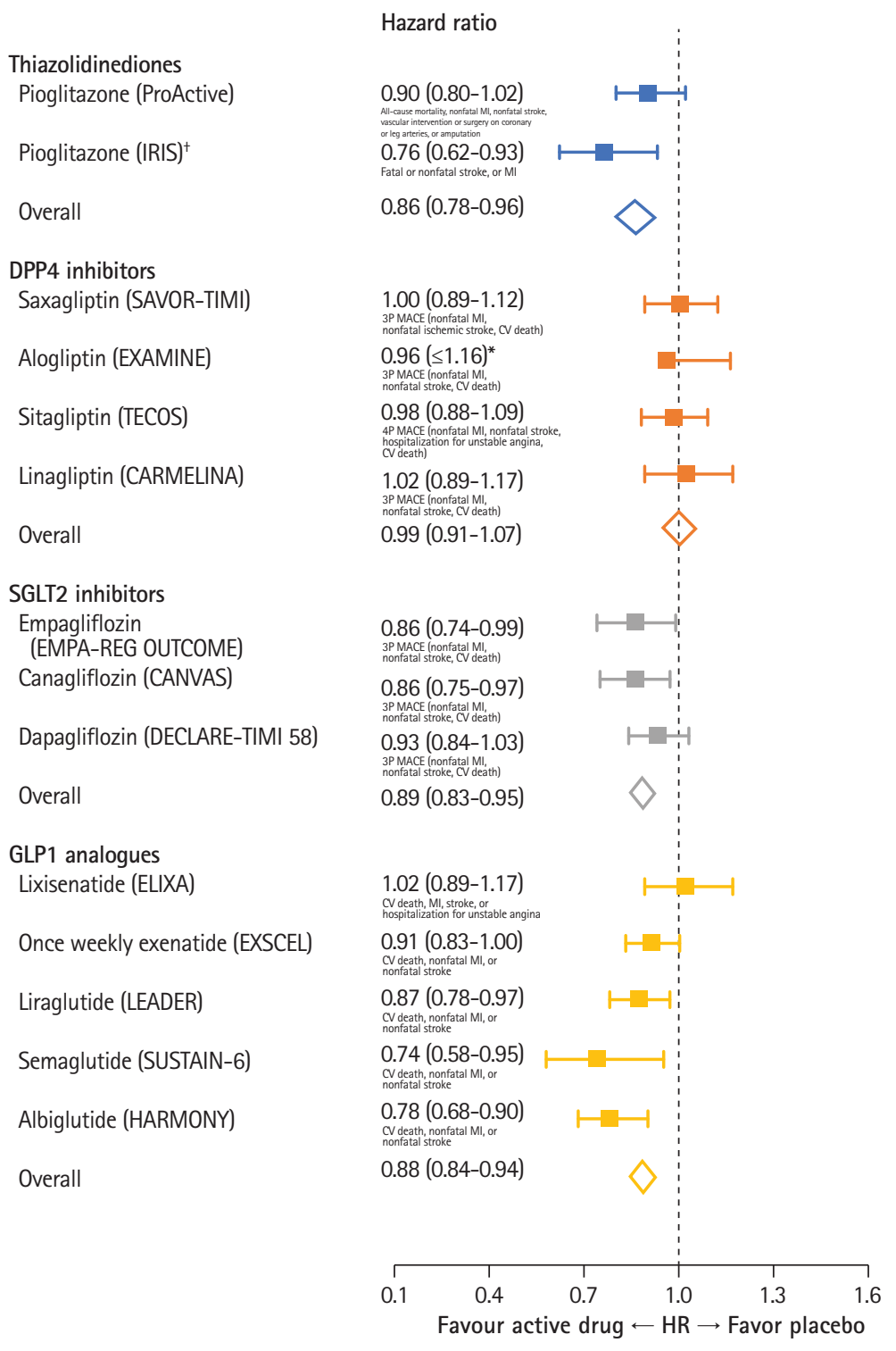

\section{Stroke}

Hazard ratio

$\underset{\text { Stroke }}{0.81}(0.61-1.07)$

0.82 (0.61-1.10)

0.81 (0.66-1.00)

1.11 (0.88-1.39)

0.91 (0.55-1.50)

$\underset{\substack{0.97 \\ \text { Fatal or nonfatal stroke }}}{0.79-1.19)}$

O.88 (0.63-1.23)

$1.02(0.88-1.18)$

$1.18(0.89-1.56)$

0.87 (0.69-1.09)

Fatal or onoffatal stroke

1.01 (0.84-1.21)

1.00 (0.88-1.13)

$1.12(0.79-1.58)$

$0.85(0.70-1.03)$

$0.86(0.71-1.06)$

Fatal or nonfatal strtoke, or
transient ischemic attack

$0.61(0.38-0.99)$

Nonfatal stroke

0.86 (0.66-1.14)

$0.86(0.77-0.97)$
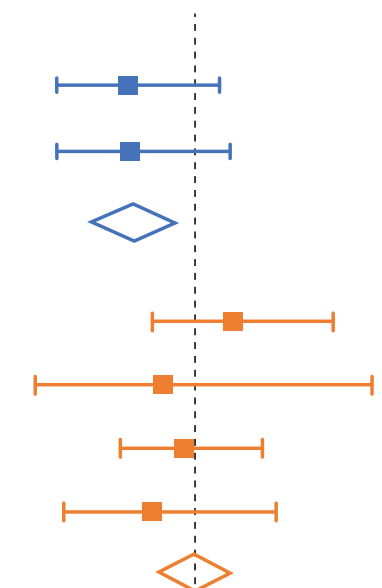

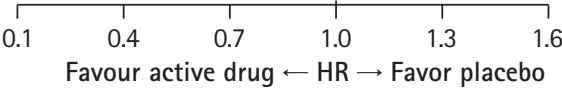

Figure 3. Effect of thiazolidinedione and novel antidiabetic agents on primary cardiovascular outcome and stroke. The hazard ratios (HRs) with 95\% confidence intervals $(\mathrm{Cls})$ are provided for the active drug compared with the placebo. Primary cardiovascular outcomes are slightly different in each study. The overall effects were calculated using fixed effects models unless there was a significant heterogeneity among trials. Heterogeneity of the clinical trials was assessed using Cochran's $Q$ test and Higgins and Thompson's $I^{2}\left(P<0.05\right.$ or $I^{2}>50$ were considered as indicative of significant heterogeneity). Analyses were performed using R version 3.5.1 (R Foundation for Statistical Computing). PROactive, PROspective pioglitAzone Clinical Trial In macroVascular Events; IRIS, Insulin Resistance Intervention after Stroke; MI, myocardial infarction; DPP4, dipeptidyl peptidase-4; SAVOR-TIMI, Saxagliptin Assessment of Vascular Outcomes Recorded in Patients with Diabetes Mellitus-Thrombolysis in Myocardial Infarction; MACE, major adverse cardiovascular event; CV, cardiovascular; EXAMINE, Examination of Cardiovascular Outcomes with Alogliptin versus Standard of Care; TECOS, Trial Evaluating Cardiovascular Outcomes with Sitagliptin; CARMELINA, Cardiovascular and Renal Microvascular Outcome Study With Linagliptin in Patients With Type 2 Diabetes Mellitus; SGLT2, sodium-glucose cotransporter-2; EMPA-REG OUTCOME, Empagliflozin, Cardiovascular Outcomes, and Mortality in Type 2 Diabetes; CANVAS, CANagliflozin CardioVascular Assessment Study; DECLARE-TIMI58, Dapagliflozin Effect on CardiovascuLAR Events-Thrombolysis in Myocardial Infarction 58; GLP1, glucagon-like peptide-1; ELIXA, Evaluation of Lixisenatide in Acute Coronary Syndrome; EXSCEL, Exenatide Study of Cardiovascular Event Lowering; LEADER, Liraglutide Effect and Action in Diabetes: Evaluation of Cardiovascular Outcome Results; SUSTAIN-6, Trial to Evaluate Cardiovascular and Other Long-term Outcomes with Semaglutide 6; HARMONY, albiglutide and cardiovascular outcomes in patients with type 2 diabetes and cardiovascular disease. *The parenthetical value is the upper boundary of the one-sided repeated $\mathrm{Cl}_{\text {, at an a-level of } 0.01 ;}{ }^{+} \mathrm{IRIS}$ study recruited participants with insulin resistance, but without type 2 diabetes mellitus. 
occurrence of stroke and myocardial infarction (event rate: $9.0 \%$ in the pioglitazone group vs. $11.8 \%$ in the placebo group; $\mathrm{HR}, 0.76 ; 95 \% \mathrm{Cl}, 0.62$ to 0.93 ) (Figure 3$).^{26}$ However, the rate of stroke alone did not differ between the pioglitazone and placebo groups (HR, $0.82 ; 95 \% \mathrm{Cl}, 0.61$ to 1.10) (Figure 3).

In a review of RCTs that compared TZDs and placebo for the secondary prevention of stroke and related vascular events in people who had experienced stroke or TIA, TZD reduced stroke recurrence (relative risk, $0.52 ; 95 \% \mathrm{Cl}, 0.34$ to 0.80 ). ${ }^{27}$ Therefore, TZDs may reduce recurrent stroke and related vascular event risk both in patients with $\mathrm{T} 2 \mathrm{D}$ and in those with insulin resistance.

\section{DPP4 inhibitors}

DPP4 inhibitors are new antidiabetic agents for $\mathrm{T}^{2} \mathrm{D}^{28}$ that do not induce hypoglycemia or weight gain. Although these and GLP1 analogues have similar incretin-based activities, their effects on cardiovascular disease risk differ. ${ }^{29}$ Cardiovascular safety trials of DPP4 inhibitors such as saxagliptin, ${ }_{1}^{30}$ alogliptin, ${ }_{1}^{31}$ sitagliptin, ${ }^{32}$ and linagliptin ${ }^{33}$ showed neutral effects on the composite outcome of cardiovascular mortality, nonfatal myocardial infarction, and nonfatal stroke. Besides these safety trials, ${ }_{1}^{30-32}$ no study has focused on the effects of DPP4 inhibitors on the primary or secondary prevention of stroke alone. HRs for the outcome of ischemic stroke, nonfatal stroke, and fatal or nonfatal stroke were 1.11 (95\% Cl, 0.88 to 1.39; $P=0.38), 0.91(95 \% \mathrm{Cl}$, 0.55 to $1.50 ; P=0.71), 0.97(95 \% \mathrm{Cl}, 0.79$ to $1.19 ; P=0.76)$, and $1.02(95 \% \mathrm{Cl}, 0.89$ to $1.17 ; P=0.74)$ for saxagliptin, alogliptin, sitagliptin, and linagliptin, respectively (Figure 3).

\section{SGLT2 inhibitors}

SGLT2 inhibitors are emerging antidiabetic agents ${ }^{34}$ that show cardiovascular benefits. Empagliflozin resulted in a beneficial cardiovascular outcome in the Empagliflozin, Cardiovascular Outcomes, and Mortality in Type 2 Diabetes (EMPA-REG OUTCOME) trial. ${ }^{35}$ The primary composite outcome, including death from cardiovascular causes, nonfatal myocardial infarction, or nonfatal stroke, occurred in $10.5 \%$ of patients in the empagliflozin group and $12.1 \%$ of those in the placebo group (HR, $0.86 ; 95.02 \% \mathrm{Cl}, 0.74$ to 0.99 ). Cardiovascular risk was reduced as early as 6 months, suggesting the cardiovascular benefit associated with empagliflozin is unlikely to be induced by its glucose-lowering properties. Furthermore, empagliflozin therapy was associated with an increased but nonsignificant risk of ischemic stroke ( $\mathrm{HR}, 1.24 ; 95 \% \mathrm{Cl}, 0.92$ to $1.67 ; P=0.16)$.

The CANagliflozin CardioVascular Assessment Study (CANVAS) program showed that patients treated with canagliflozin had a lower risk of cardiovascular events than those who received the placebo. However, canagliflozin showed no benefit in preventing stroke, although the point estimate was $<1$ for fatal or nonfatal stroke compared with the placebo $(H R, 0.87$; $95 \% \mathrm{Cl}, 0.69$ to 1.09$)^{36}$

In the Dapagliflozin Effect on CardiovascuLAR Events-Thrombolysis in Myocardial Infarction 58 (DECLARE-TIMI58) study, $40.6 \%$ of participants showed established atherosclerotic cardiovascular disease and 59.4\% had multiple cardiovascular risk factors. Dapagliflozin therapy was not superior in terms of the original primary cardiovascular outcome $(\mathrm{HR}, 0.93 ; 95 \% \mathrm{Cl}, 0.84$ to 1.03) but showed benefits in reducing the risk of cardiovascular mortality or hospitalization for heart failure $(H R, 0.83$; $95 \% \mathrm{Cl}, 0.73$ to 0.95$).{ }^{37}$ The point estimates for ischemic stroke were similar in the dapagliflozin and placebo arms (HR, 1.01; $95 \% \mathrm{Cl}, 0.84$ to 1.21 ) (Figure 3).

A recent population-based observational study showed that SGLT2 inhibitors (dapagliflozin, empagliflozin, or canagliflozin) were associated with reduced cardiovascular mortality compared to other glucose-lowering drugs $(\mathrm{HR}, 0.53 ; 95 \% \mathrm{Cl}, 0.40$ to $0.71 ; P<0.05) .{ }^{38}$ Furthermore, no difference in nonfatal stroke risk was observed between the groups treated with the SGLT2 inhibitor and placebo ( $\mathrm{HR}, 0.86 ; 95 \% \mathrm{Cl}, 0.72$ to 1.04$)$. A meta-analysis of SGLT2 inhibitors and stroke risk also showed the neutral effects of SGLT2 inhibitors on stroke risk compared to that of the placebo. ${ }^{39}$ Evidence therefore suggests that SGLT2 inhibitor use is associated with reduced rates of cardiovascular events and mortality. However, in cardiovascular outcome trials, SGLT2 inhibitors showed inconsistent or nonsignificant effects on stroke risk.

\section{GLP1 analogues}

Among five GLP1 analogues evaluated, liraglutide, ${ }^{40}$ semaglutide $_{1}{ }^{41}$ and albiglutide ${ }^{42}$ showed superiority in terms of composite cardiovascular outcome. In the Liraglutide Effect and Action in Diabetes: Evaluation of Cardiovascular Outcome Results $\left(\right.$ LEADER $^{40}$ trial, the HR for fatal or nonfatal stroke was 0.86 ( $95 \% \mathrm{Cl}, 0.71$ to $1.06 ; P=0.16)$ in the liraglutide-treated group. In the Trial to Evaluate Cardiovascular and Other Long-term Outcomes with Semaglutide (SUSTAIN)- 6 trial, ${ }^{41}$ the HR for nonfatal stroke was $0.61(95 \% \mathrm{Cl}, 0.38$ to $0.99 ; P=0.04)$ in the semaglutide-treated group (Figure 3). The Harmony Outcomes study reported the superiority of albiglutide therapy in terms of the cardiovascular composite outcome $(\mathrm{HR}, 0.78 ; 95 \% \mathrm{Cl}, 0.68$ to 0.90 ) but not of stroke (HR, $0.86 ; 95 \% \mathrm{Cl}, 0.66$ to 1.14$){ }^{42}$

In contrast, lixisenatide treatment (Evaluation of Lixisenatide in Acute Coronary Syndrome [ELIXA] study) ${ }^{43}$ and once-weekly exenatide treatment (Exenatide Study of Cardiovascular Event Lowering [EXSCEL] study) ${ }^{44}$ were not superior in terms of stroke prevention or primary cardiovascular outcome. Therefore, stud- 
ies of GLP1 analogues have produced inconsistent results for primary cardiovascular outcome, and their effects on stroke remain unclear.

\section{Effects of individual antidiabetic agents on stroke}

\section{TZDs}

TZD is an agonist of peroxisome proliferator-activated receptor- $\gamma$ (PPAR $\gamma)$, a nuclear receptor that regulates the transcription of genes involved in glucose and lipid metabolism. TZD increases insulin sensitivity in muscle and adipose tissue. However, PPARy is expressed ubiquitously in other tissues and TZD exerts various pleiotropic effects. In terms of cerebrovascular diseases, TZD has both neuroprotective and antiatherosclerotic effects.

TZD improves the survival of neurons and glial cells, especially microglia, by reducing neuroinflammation. ${ }^{45,46}$ Accordingly, TZD is protective against both ischemic and excitotoxic neuronal stress. ${ }^{47}$ In mouse models of oxygen/glucose deprivation or glutamate/N-methyl-D-aspartate toxicity, PPARy activation reduced neuronal death. However, mice lacking PPARY in neurons were more susceptible to ischemic damage caused by focal cerebral ischemia. ${ }^{48}$

TZD also prevents atherosclerosis progression. In vivo studies of atherosclerosis have shown the antiatherosclerotic effects of TZDs. Rosiglitazone reduced atherosclerosis development in LDL-receptor-deficient mice. ${ }^{49}$ Lobeglitazone, another TZD, reduced atheroma burden in a balloon-injury model using highfat and high-fructose diet-fed apolipoprotein E (apoE)-knockout mice. ${ }^{50}$ These antiatherosclerotic effects may be independent of TZD's metabolic effects. Rosiglitazone showed beneficial effects on atherosclerosis independent of its effects on glucose and lipid levels in insulin-insufficient streptozotocintreated apoE-knockout mice. ${ }^{51}$ TZD can act on monocytes, endothelial cells, and vascular smooth muscle cells, which are crucial in the pathogenesis of atherosclerosis. TZD reduces proinflammatory cytokine production in monocytes, reduces adhesion molecule and chemokine expression in endothelial cells, and suppresses vascular smooth muscle cell proliferation and migration. ${ }^{52}$ Collectively, these effects may contribute to TZD's antiatherosclerotic properties.

There are few human mechanistic studies available, but TZD has also been shown to improve endothelial function in humans. In an RCT of patients with impaired glucose tolerance, endothelial function measured by brachial artery flow-mediated dilation improved after treatment with pioglitazone at 30 $\mathrm{mg} /$ day for 12 weeks. $^{53}$

\section{DPP4 inhibitors}

DPP4 inhibitors increase circulating active GLP1 levels twofold, and potential antiatherosclerotic effects of DPP4 inhibitors may occur through GLP1 action. In apoE-knockout mice fed a high-fat diet, sitagliptin treatment decreased atherosclerotic plaque burden. ${ }^{54,55}$ However, in human studies, results were inconsistent. In two RCTs, alogliptin and sitagliptin therapy both attenuated the progression of carotid IMT, as measured via carotid ultrasonography. ${ }^{56,57}$ Conversely, another RCT of sitagliptin showed no effects on carotid IMT. ${ }^{58}$ In animal studies, DPP4 inhibitors also showed direct antistroke effects. In highfat diet-fed obese diabetic mice, linagliptin reduced brain infarct volume after middle cerebral artery occlusion, whereas glimepiride did not reduce brain ischemic lesions despite the greater attenuation of hyperglycemia. ${ }^{59}$

Several basic cell studies support the antiatherosclerotic effects of DPP4 inhibitors. Direct treatment of human vascular endothelial cells with sitagliptin decreased tumor necrosis factor-a-induced upregulation of adhesion molecules. ${ }^{60} \mathrm{An}$ other in vitro study showed that sitagliptin decreased the production of ROS and increased endothelial NO synthase expression in endothelial cells. ${ }^{61}$ Therefore, the antiatherosclerotic effects of DPP4 inhibitors may be explained by their anti-inflammatory and antioxidant properties. ${ }^{62}$

GLP1 is not the only substrate of DPP4. DPP4 inactivates various peptide hormones including glucose-dependent insulinotropic polypeptide, B-type natriuretic peptide, stromal cellderived factor-1a (SDF1a), and substance $P^{63}$ In a recent study of mice, linagliptin treatment increased active SDF1a levels in brain tissue, and blockade of the SDF1a-C-X-C chemokine receptor type 4 (CXCR4) pathway with a specific antagonist abolished the positive effects of linagliptin on functional outcomes after stroke. ${ }^{64}$

\section{SGLT2 inhibitors}

SGLT2 inhibitors reduce hyperglycemia by bypassing the action of insulin and inducing glycosuria, and by reducing body weight and blood pressure. ${ }^{65}$ This unique mode of action modulates both hyperinsulinemia and conventional cardiovascular risk factors, including visceral obesity and albuminuria. ${ }^{66}$ We recently showed that the atheromatous plaque area in the aortic arch was significantly smaller after empagliflozin treatment than after sulfonylurea treatment in atherosclerosis-prone mice. ${ }^{67} \mathrm{An}$ other study showed that empagliflozin treatment mitigated coronary artery thickening and remodeling and vascular dysfunction in $d b / d b$ mice. ${ }^{68}$ Interestingly, SGLT2 inhibitors induce hyperketonemia, which may provide a "thrifty substrate" and lead to cardioprotective effects. ${ }^{69}$ Increased ketone levels may 
also directly affect the risk of stroke. In rodent studies, $\beta$-hydroxybutyrate, a ketone body that is increased after SGLT2 inhibitor treatment, could reduce brain infarct size by activating neuroprotective macrophages, and shift glucose metabolism toward reducing oxidative stress. ${ }^{70,71}$ Therefore, the diverse metabolic and hemodynamic effects of SGLT2 inhibitors appear to protect the cardiovascular system, ${ }_{1}^{72}$ although it is unclear whether this also applies to the cerebrovascular system.

However, in the EMPA-REG OUTCOME trial, empagliflozin treatment slightly increased stroke risk. ${ }^{35}$ Dehydration and/or increased hematocrit was a proposed mechanism for this finding. However, studies of two other SGLT2 inhibitors reported inconsistent results: decreased stroke risk was observed in the canagliflozin group in the CANVAS program ${ }^{36}$ and a neutral effect was observed in the dapagliflozin group in the DECLARETIMI58 study. ${ }^{37}$ So far, it is unclear whether this is a class effect or that of individual drugs. Therefore, mechanistic studies of SGLT inhibitors are warranted.

\section{GLP1 analogues}

The cardioprotective effects of GLP1 have been consistently reported in preclinical studies, including endothelial function modulation via macrophage inflammatory response inhibition, ${ }^{73}$ increased endothelial NO production, reduced vascular adhesion molecule release, ${ }^{74}$ and suppressed vascular cell migration. ${ }^{75}$ In an atherosclerotic mouse model, a 4-week infusion of GLP1(7-36) amide, an active form of GLP1, suppressed atherosclerosis development and macrophage infiltration in the aortic wall. ${ }^{76}$ This effect was blocked by co-infusion with exendin(9-39), a specific GLP1 receptor antagonist, suggesting that GLP1 analogues exert an antiatherosclerotic effect through the GLP1 canonical receptor.

The antiatherosclerotic or vasculoprotective effects of GLP1 and GLP1 analogues have also been observed in rodent stroke models. ${ }^{77-79}$ After cerebral ischemia-reperfusion injury, intraperitoneal or intracerebroventricular administration of liraglutide, a GLP1 analogue, consistently reduced the cerebral infarct volume in rats. ${ }^{78}$ These neuroprotective effects are induced by increasing antioxidant effects, upregulating vascular endothelial growth factor production, ${ }^{78}$ and reducing proinflammatory cyclooxygenase- 2 and prostaglandin E2 concentrations. ${ }^{79}$ These findings suggest that GLP1 analogues play a favorable role in the cardiovascular system through glucoregulatory, antiatherosclerotic, anti-inflammatory, and blood pressure-lowering effects, and by improving endothelial function. ${ }^{80}$

\section{Conclusions}

So far, evidence suggests that optimal glucose control without inducing hypoglycemia has beneficial effects in the treatment of cardiovascular diseases including stroke. Accordingly, international guidelines for diabetes management recommend achieving a glycemic target goal to prevent or delay both micro- and macrovascular complications. ${ }^{81,82}$

Several recent large-scale studies of new antidiabetic medications suggest that these agents have beneficial effects in preventing the development of composite cardiovascular outcome and/or related mortality. However, their effects on stroke remain unclear. Empagliflozin treatment in the EMPA-REG OUTCOME trial showed a nonsignificant increase in stroke incidence ${ }_{1}^{35}$ although this contrasted with the effects of canagliflozin in the CANVAS program (nonsignificant decrease) ${ }^{36}$ and dapagliflozin in the DECLARE-TIMI58 study (neutral). ${ }^{37}$

Although the semaglutide trial showed significant beneficial effects on nonfatal stroke, the cardiovascular outcome trials were underpowered for the specific stroke endpoints. More studies using ertugliflozin (SGLT2 inhibitor) and dulaglutide (once-weekly GLP1 analogue) are currently ongoing in the hope of improving vascular outcomes and total mortality in patients with diabetes at high stroke risk. ${ }^{83,84}$ Until the results of these studies are released, multifactorial interventions targeting individual cerebrovascular risk factors are required to improve clinical outcomes in diabetes patients after a stroke or at high risk of stroke. More mechanistic studies focusing on the mechanisms underlying the effects of these agents on stroke risk are needed.

\section{Disclosure}

The authors have no financial conflicts of interest.

\section{Acknowledgments}

This work was supported by the Korean Diabetes Association and Seoul National University Bundang Hospital.

\section{References}

1. Gaede P, Lund-Andersen $H$, Parving HH, Pedersen 0 . Effect of a multifactorial intervention on mortality in type 2 diabetes. N Eng/J Med 2008;358:580-591.

2. Yang $Y$, Yao JJ, Du JL, Bai $R$, Sun $L P$, Sun $G H$, et al. Primary prevention of macroangiopathy in patients with short-duration type 2 diabetes by intensified multifactorial interven- 
tion: seven-year follow-up of diabetes complications in Chinese. Diabetes Care 2013;36:978-984.

3. Griffin SJ, Borch-Johnsen K, Davies MJ, Khunti K, Rutten GE, Sandbæk $A$, et al. Effect of early intensive multifactorial therapy on 5-year cardiovascular outcomes in individuals with type 2 diabetes detected by screening (ADDITION-Europe): a cluster-randomised trial. Lancet 2011;378:156-167.

4. Stead LG, Gilmore RM, Bellolio MF, Mishra S, Bhagra A, Vaid-

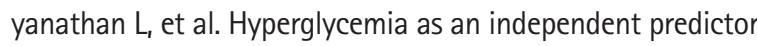
of worse outcome in non-diabetic patients presenting with acute ischemic stroke. Neurocrit Care 2009;10:181-186.

5. Emerging Risk Factors Collaboration, Sarwar N, Gao P, Seshasai SR, Gobin R, Kaptoge $S$, et al. Diabetes mellitus, fasting blood glucose concentration, and risk of vascular disease: a collaborative meta-analysis of 102 prospective studies. Lancet 2010;375:2215-2222.

6. Saxena $A$, Anderson CS, Wang $X$, Sato $S$, Arima $H_{1}$ Chan $E_{1}$ et al. Prognostic significance of hyperglycemia in acute intracerebral hemorrhage: the INTERACT2 study. Stroke 2016; 47:682-688.

7. Luchsinger JA, Tang MX, Stern $Y$, Shea $S$, Mayeux R. Diabetes mellitus and risk of Alzheimer's disease and dementia with stroke in a multiethnic cohort. Am J Epidemiol 2001;154: 635-641.

8. Schmidt AM, Yan SD, Wautier JL, Stern D. Activation of receptor for advanced glycation end products: a mechanism for chronic vascular dysfunction in diabetic vasculopathy and atherosclerosis. Circ Res 1999;84:489-497.

9. Baynes JW, Thorpe SR. Role of oxidative stress in diabetic complications: a new perspective on an old paradigm. Diabetes 1999;48:1-9.

10. Idris I, Gray S, Donnelly R. Protein kinase $C$ activation: isozyme-specific effects on metabolism and cardiovascular complications in diabetes. Diabetologia 2001;44:659-673.

11. Rösen $P$, Nawroth PP, King G, Möller W, Tritschler HJ, Packer $\mathrm{L}$. The role of oxidative stress in the onset and progression of diabetes and its complications: a summary of a Congress Series sponsored by UNESCO-MCBN, the American Diabetes Association and the German Diabetes Society. Diabetes Metab Res Rev 2001;17:189-212.

12. Hennes MM, O'Shaughnessy IM, Kelly TM, LaBelle P, Egan $\mathrm{BM}$, Kissebah AH. Insulin-resistant lipolysis in abdominally obese hypertensive individuals. Role of the renin-angiotensin system. Hypertension 1996;28:120-126.

13. Beckman JA, Creager MA, Libby P. Diabetes and atherosclerosis: epidemiology, pathophysiology, and management. JAMA 2002;287:2570-2581.

14. Ishii $H_{1}$ Jirousek MR, Koya $D$, Takagi $C$, Xia $P$, Clermont $A$, et al. Amelioration of vascular dysfunctions in diabetic rats by an oral PKC beta inhibitor. Science 1996;272:728-731.

15. Guerrero-Romero F, Rodríguez-Morán M. Proteinuria is an independent risk factor for ischemic stroke in non-insulindependent diabetes mellitus. Stroke 1999;30:1787-1791.

16. Töyry JP, Niskanen LK, Länsimies EA, Partanen KP, Uusitupa MI. Autonomic neuropathy predicts the development of stroke in patients with non-insulin-dependent diabetes mellitus. Stroke 1996;27:1316-1318.

17. Cheung N, Rogers S, Couper DJ, Klein R, Sharrett AR, Wong TY. Is diabetic retinopathy an independent risk factor for ischemic stroke? Stroke 2007;38:398-401.

18. Gaede $P$, Vedel $P$, Larsen $N$, Jensen GV, Parving $H H$, Pedersen 0 . Multifactorial intervention and cardiovascular disease in patients with type 2 diabetes. N Engl J Med 2003;348:383393.

19. Ueki K, Sasako T, Okazaki Y, Kato M, Okahata S, Katsuyama $H$, et al. Effect of an intensified multifactorial intervention on cardiovascular outcomes and mortality in type 2 diabetes (J-DOIT3): an open-label, randomised controlled trial. Lancet Diabetes Endocrinol 2017;5:951-964.

20. Bree AJ, Puente EC, Daphna-Iken D, Fisher SJ. Diabetes increases brain damage caused by severe hypoglycemia. Am J Physiol Endocrinol Metab 2009;297:E194-E201.

21. Lee $M$, Saver JL, Hong KS, Song $S$, Chang KH, Ovbiagele B. Effect of pre-diabetes on future risk of stroke: meta-analysis. BMJ 2012;344:e3564.

22. Sidhu JS, Kaposzta Z, Markus HS, Kaski JC. Effect of rosiglitazone on common carotid intima-media thickness progression in coronary artery disease patients without diabetes mellitus. Arterioscler Thromb Vasc Biol 2004;24:930-934.

23. Langenfeld $M R$, Forst $T$, Hohberg $C_{1}$ Kann $P$, Lübben $G$, Konrad $T$, et al. Pioglitazone decreases carotid intima-media thickness independently of glycemic control in patients with type 2 diabetes mellitus: results from a controlled randomized study. Circulation 2005;111:2525-2531.

24. Dormandy JA, Charbonnel B, Eckland DJ, Erdmann E, MassiBenedetti M, Moules IK, et al. Secondary prevention of macrovascular events in patients with type 2 diabetes in the PROactive study (PROspective pioglitAzone Clinical Trial In macroVascular Events): a randomized controlled trial. Lancet 2005;366:1279-1289.

25. Wilcox R, Bousser MG, Betteridge DJ, Schernthaner G, Pirags $V$, Kupfer $S$, et al. Effects of pioglitazone in patients with type 2 diabetes with or without previous stroke: results from PROactive (PROspective pioglitAzone Clinical Trial In macroVascular Events 04). Stroke 2007;38:865-873.

26. Kernan $W N$, Viscoli $C M$, Furie $K L_{1}$ Young $L H$, Inzucchi $S E_{\text {, }}$ 
Gorman $\mathrm{M}$, et al. Pioglitazone after ischemic stroke or transient ischemic attack. N Engl J Med 2016;374:1321-1331.

27. Liu J, Wang LN. Peroxisome proliferator-activated receptor gamma agonists for preventing recurrent stroke and other vascular events in patients with stroke or transient ischaemic attack. Cochrane Database Syst Rev 2015;(10):CD010693.

28. Yusta B, Baggio LL, Estall JL, Koehler JA, Holland DP, Li H, et al. GLP-1 receptor activation improves beta cell function and survival following induction of endoplasmic reticulum stress. Cell Metab 2006;4:391-406.

29. Nauck MA, Meier JJ, Cavender MA, Abd El Aziz M, Drucker DJ. Cardiovascular actions and clinical outcomes with glucagon-like peptide-1 receptor agonists and dipeptidyl peptidase-4 inhibitors. Circulation 2017;136:849-870.

30. Scirica BM, Bhatt DL, Braunwald E, Steg PG, Davidson J, Hirshberg B, et al. Saxagliptin and cardiovascular outcomes in patients with type 2 diabetes mellitus. N Engl J Med 2013; 369:1317-1326.

31. White WB, Cannon CP, Heller SR, Nissen SE, Bergenstal RM, Bakris $\mathrm{GL}$, et al. Alogliptin after acute coronary syndrome in patients with type 2 diabetes. N Engl J Med 2013;369:13271335.

32. Green JB, Bethel MA, Armstrong PW, Buse JB, Engel SS, Garg $J$, et al. Effect of sitagliptin on cardiovascular outcomes in type 2 diabetes. N Engl J Med 2015;373:232-242.

33. Rosenstock J, Perkovic V, Johansen OE, Cooper ME, Kahn SE, Marx $N$, et al. Effect of linagliptin vs placebo on major cardiovascular events in adults with type 2 diabetes and high cardiovascular and renal risk: the CARMELINA randomized clinical trial. JAMA 2019;321:69-79.

34. Kalra S. Sodium glucose co-transporter-2 (SGLT2) inhibitors: a review of their basic and clinical pharmacology. Diabetes Ther 2014:5:355-366.

35. Zinman B, Wanner C, Lachin JM, Fitchett D, Bluhmki E, Hantel $\mathrm{S}$, et al. Empagliflozin, cardiovascular outcomes, and mortality in type 2 diabetes. N Engl J Med 2015;373:2117-2128.

36. Neal B, Perkovic V, Mahaffey KW, de Zeeuw D, Fulcher G, Erondu $\mathrm{N}$, et al. Canagliflozin and cardiovascular and renal events in type 2 diabetes. N Engl J Med 2017;377:644-657.

37. Wiviott SD, Raz I, Bonaca MP, Mosenzon O, Kato ET, Cahn A, et al. Dapagliflozin and cardiovascular outcomes in type 2 diabetes. N Engl J Med 2019;380:347-357.

38. Birkeland $\mathrm{KI}$, Jørgensen $\mathrm{ME}$, Carstensen $\mathrm{B}$, Persson $\mathrm{F}$, Gulseth $\mathrm{HL}$, Thuresson $\mathrm{M}$, et al. Cardiovascular mortality and morbidity in patients with type 2 diabetes following initiation of sodium-glucose co-transporter-2 inhibitors versus other glucose-lowering drugs (CVD-REAL Nordic): a multinational observational analysis. Lancet Diabetes Endocrinol 2017;5:709-
717.

39. Guo M, Ding J, Li J, Wang J, Zhang T, Liu C, et al. SGLT2 inhibitors and risk of stroke in patients with type 2 diabetes: a systematic review and meta-analysis. Diabetes Obes Metab 2018;20:1977-1982.

40. Marso SP, Daniels GH, Brown-Frandsen K, Kristensen P, Mann JF, Nauck MA, et al. Liraglutide and cardiovascular outcomes in type 2 diabetes. N Engl J Med 2016;375:311-322.

41. Marso SP, Bain SC, Consoli A, Eliaschewitz FG, Jódar E, Leiter $L A$, et al. Semaglutide and cardiovascular outcomes in patients with type 2 diabetes. N Engl J Med 2016;375:18341844.

42. Hernandez AF, Green JB, Janmohamed $S$, D'Agostino RB Sr,

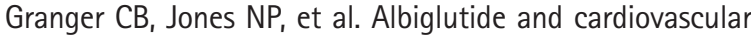
outcomes in patients with type 2 diabetes and cardiovascular disease (Harmony Outcomes): a double-blind, randomised placebo-controlled trial. Lancet 2018;392:1519-1529.

43. Pfeffer MA, Claggett B, Diaz R, Dickstein K, Gerstein HC, Køber LV, et al. Lixisenatide in patients with type 2 diabetes and acute coronary syndrome. N Engl J Med 2015;373:22472257.

44. Holman RR, Bethel MA, Mentz RJ, Thompson VP, Lokhnygina $Y$, Buse JB, et al. Effects of once-weekly exenatide on cardiovascular outcomes in type 2 diabetes. N Engl J Med 2017; 377:1228-1239.

45. Pérez MJ, Quintanilla RA. Therapeutic actions of the thiazolidinediones in Alzheimer's disease. PPAR Res 2015;2015: 957248.

46. Barbier O, Torra IP, Duguay Y, Blanquart C, Fruchart JC, Glineur $C_{\text {, et }}$ al. Pleiotropic actions of peroxisome proliferatoractivated receptors in lipid metabolism and atherosclerosis. Arterioscler Thromb Vasc Biol 2002;22:717-726.

47. Shimazu T, Inoue I, Araki N, Asano Y, Sawada M, Furuya D, et al. A peroxisome proliferator-activated receptor-gamma agonist reduces infarct size in transient but not in permanent ischemia. Stroke 2005;36:353-359.

48. Zhao X, Strong R, Zhang J, Sun G, Tsien JZ, Cui Z, et al. Neuronal PPARgamma deficiency increases susceptibility to brain damage after cerebral ischemia. J Neurosci 2009;29:61866195.

49. Li AC, Brown KK, Silvestre MJ, Willson TM, Palinski W, Glass CK. Peroxisome proliferator-activated receptor gamma ligands inhibit development of atherosclerosis in LDL receptordeficient mice. J Clin Invest 2000;106:523-531.

50. Lim S, Lee KS, Lee JE, Park HS, Kim KM, Moon JH, et al. Effect of a new PPAR-gamma agonist, lobeglitazone, on neointimal formation after balloon injury in rats and the development of atherosclerosis. Atherosclerosis 2015;243:107-119. 
51. Calkin AC, Forbes JM, Smith CM, Lassila M, Cooper ME, Jandeleit-Dahm KA, et al. Rosiglitazone attenuates atherosclerosis in a model of insulin insufficiency independent of its metabolic effects. Arterioscler Thromb Vasc Biol 2005;25: 1903-1909.

52. Wang N, Yin R, Liu Y, Mao G, Xi F. Role of peroxisome proliferator-activated receptor- $\gamma$ in atherosclerosis: an update. Circ J 2011;75:528-535.

53. Quinn $\mathrm{CE}$, Lockhart $\mathrm{CJ}$, Hamilton $\mathrm{PK}$, Loughrey $\mathrm{CM}$, McVeigh GE. Effect of pioglitazone on endothelial function in impaired glucose tolerance. Diabetes Obes Metab 2010;12:709-715.

54. Zeng Y, Li C, Guan M, Zheng Z, Li J, Xu W, et al. The DPP-4 inhibitor sitagliptin attenuates the progress of atherosclerosis in apolipoprotein-E-knockout mice via AMPK- and MAPKdependent mechanisms. Cardiovasc Diabetol 2014;13:32.

55. Matsubara J, Sugiyama S, Sugamura K, Nakamura T, Fujiwara $Y$, Akiyama $E_{1}$ et al. A dipeptidyl peptidase-4 inhibitor, desfluoro-sitagliptin, improves endothelial function and reduces atherosclerotic lesion formation in apolipoprotein E-deficient mice. J Am Coll Cardiol 2012;59:265-276.

56. Mita T, Katakami N, Shimomura I, Watada H. Response to comment on Mita et al. Sitagliptin attenuates the progression of carotid intima-media thickening in insulin-treated patients with type 2 diabetes: the sitagliptin preventive study of intima-media thickness evaluation (SPIKE). A randomized controlled trial. Diabetes Care 2016;39:455-464. Diabetes Care 2016;39:e104-e105.

57. Mita $T$, Katakami $N$, Yoshii $H_{1}$ Onuma $T$, Kaneto $H$, Osonoi $T$, et al. Alogliptin, a dipeptidyl peptidase 4 inhibitor, prevents the progression of carotid atherosclerosis in patients with type 2 diabetes: the study of preventive effects of alogliptin on diabetic atherosclerosis (SPEAD-A). Diabetes Care 2016;39:139-148.

58. Oyama J, Murohara T, Kitakaze M, Ishizu T, Sato Y, Kitagawa $K$, et al. The effect of sitagliptin on carotid artery atherosclerosis in type 2 diabetes: the PROLOGUE randomized controlled trial. PLoS Med 2016;13:e1002051.

59. Darsalia V, Ortsäter $H$, Olverling A, Darlöf E, Wolbert P, Nyström $T$, et al. The DPP-4 inhibitor linagliptin counteracts stroke in the normal and diabetic mouse brain: a comparison with glimepiride. Diabetes 2013;62:1289-1296.

60. Hu Y, Liu H, Simpson RW, Dear AE. GLP-1-dependent and independent effects and molecular mechanisms of a dipeptidyl peptidase 4 inhibitor in vascular endothelial cells. Mol Biol Rep 2013;40:2273-2279.

61. Ishibashi Y, Matsui T, Takeuchi M, Yamagishi S. Sitagliptin augments protective effects of GLP-1 against advanced glycation end product receptor axis in endothelial cells. Horm
Metab Res 2011;43:731-734.

62. Zhou Y, Guo Z, Yan W, Wang W. Cardiovascular effects of sitagliptin: an anti-diabetes medicine. Clin Exp Pharmacol Physiol 2018;45:628-635.

63. Fadini GP, Avogaro A. Cardiovascular effects of DPP-4 inhibition: beyond GLP-1. Vascul Pharmacol 2011;55:10-16.

64. Chiazza F, Tammen H, Pintana H, Lietzau G, Collino M, Nys-

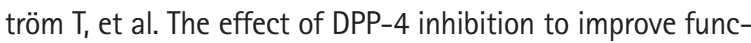
tional outcome after stroke is mediated by the SDF-1a/ CXCR4 pathway. Cardiovasc Diabetol 2018;17:60.

65. Ferrannini E, Solini A. SGLT2 inhibition in diabetes mellitus: rationale and clinical prospects. Nat Rev Endocrinol 2012;8:495502.

66. Inzucchi SE, Zinman B, Wanner C, Ferrari R, Fitchett D, Hantel $\mathrm{S}$, et al. SGLT-2 inhibitors and cardiovascular risk: proposed pathways and review of ongoing outcome trials. Diab Vasc Dis Res 2015;12:90-100.

67. Han JH, Oh TJ, Lee G, Maeng HJ, Lee DH, Kim KM, et al. The beneficial effects of empagliflozin, an SGLT2 inhibitor, on atherosclerosis in ApoE (-/-) mice fed a western diet. Diabetologia 2017;60:364-376.

68. Lin B, Koibuchi N, Hasegawa Y, Sueta D, Toyama K, Uekawa K, et al. Glycemic control with empagliflozin, a novel selective SGLT2 inhibitor, ameliorates cardiovascular injury and cognitive dysfunction in obese and type 2 diabetic mice. Cardiovasc Diabetol 2014;13:148.

69. Ferrannini E, Mark M, Mayoux E. CV protection in the EMPAREG OUTCOME trial: a "thrifty substrate" hypothesis. Diabetes Care 2016;39:1108-1114.

70. Rahman M, Muhammad S, Khan MA, Chen H, Ridder DA, Müller-Fielitz $\mathrm{H}$, et al. The $\beta$-hydroxybutyrate receptor HCA2 activates a neuroprotective subset of macrophages. Nat Commun 2014;5:3944.

71. Bazzigaluppi P, Lake EM, Beckett TL, Koletar MM, Weisspapir I, Heinen $S$, et al. Imaging the effects of $\beta$-hydroxybutyrate on peri-infarct neurovascular function and metabolism. Stroke 2018;49:2173-2181.

72. Lim S, Eckel RH, Koh KK. Clinical implications of current cardiovascular outcome trials with sodium glucose cotransporter-2 (SGLT2) inhibitors. Atherosclerosis 2018;272:33-40.

73. Arakawa M, Mita $T$, Azuma $K$, Ebato $C$, Goto $H_{1}$ Nomiyama $T_{1}$ et al. Inhibition of monocyte adhesion to endothelial cells and attenuation of atherosclerotic lesion by a glucagon-like peptide-1 receptor agonist, exendin-4. Diabetes 2010;59:10301037.

74. Gaspari T, Liu H, Welungoda I, Hu Y, Widdop RE, Knudsen LB, et al. A GLP-1 receptor agonist liraglutide inhibits endothelial cell dysfunction and vascular adhesion molecule expression in 
an ApoE-/- mouse model. Diab Vasc Dis Res $2011 ; 8: 117-124$.

75. Lim S, Lee GY, Park HS, Lee DH, Oh TJ, Kim KM, et al. Attenuation of carotid neointimal formation after direct delivery of a recombinant adenovirus expressing glucagon-like peptide-1 in diabetic rats. Cardiovasc Res 2017;113:183-194.

76. Nagashima M, Watanabe T, Terasaki M, Tomoyasu M, Nohtomi K, Kim-Kaneyama J, et al. Native incretins prevent the development of atherosclerotic lesions in apolipoprotein $\mathrm{E}$ knockout mice. Diabetologia 2011;54:2649-2659.

77. Li Y, Perry T, Kindy MS, Harvey BK, Tweedie D, Holloway HW, et al. GLP-1 receptor stimulation preserves primary cortical and dopaminergic neurons in cellular and rodent models of stroke and Parkinsonism. Proc Natl Acad Sci U S A 2009;106: 1285-1290.

78. Sato K, Kameda M, Yasuhara T, Agari T, Baba T, Wang F, et al. Neuroprotective effects of liraglutide for stroke model of rats. Int J Mol Sci 2013;14:21513-21524.

79. Kim S, Jeong J, Jung HS, Kim B, Kim YE, Lim DS, et al. Antiinflammatory effect of glucagon like peptide-1 receptor agonist, exendin-4, through modulation of IB1/JIP1 expression and JNK signaling in stroke. Exp Neurobiol 2017;26:227-239.
80. Lim S, Kim KM, Nauck MA. Glucagon-like peptide-1 receptor agonists and cardiovascular events: class effects versus individual patterns. Trends Endocrinol Metab 2018;29:238-248.

81. American Diabetes Association. 6. Glycemic targets. Diabetes Care 2017;40(Suppl 1):S48-S56.

82. Garber AJ, Abrahamson MJ, Barzilay Jl, Blonde L, Bloomgarden ZT, Bush MA, et al. Consensus statement by the American Association of Clinical Endocrinologists and American College of Endocrinology on the comprehensive type 2 diabetes management algorithm: 2017 executive summary. Endocr Pract 2017;23:207-238.

83. Franchi $F$, Rollini $F$, Aggarwal $N, H u$ J, Kureti $M$, Durairaj $A$, et al. Pharmacodynamic comparison of prasugrel versus ticagrelor in patients with type 2 diabetes mellitus and coronary artery disease: the OPTIMUS (Optimizing Antiplatelet Therapy in Diabetes Mellitus)-4 Study. Circulation 2016;134:780-792.

84. Kim JB, Joung HJ, Lee JM, Woo JS, Kim WS, Kim KS, et al. Evaluation of the vascular protective effects of new oral anticoagulants in high-risk patients with atrial fibrillation (PREFER-AF): study protocol for a randomized controlled trial. Trials 2016;17:422. 